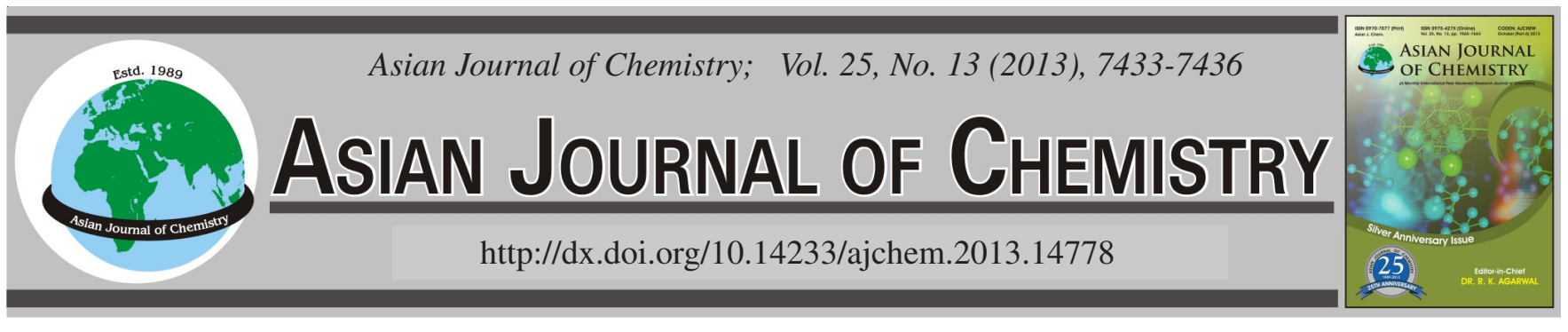

\title{
Spectrophotometric Determination of Tiapride in Pharmaceutical Formulations
}

Nawal A. Alarfaj ${ }^{*}$, AzZa A. Mostafa and Zinah A. Alghamdi

Department of Chemistry, College of Science, King Saud University, P.O. Box-22452, Riyadh 11495, Saudi Arabia

*Corresponding author: Tel/Fax: +966 14772245; E-mail: nalarfaj@ hotmail.com

(Received: 3 November 2012;

Accepted: 29 June 2013)

AJC-13722

Simple, accurate and precise spectrophotometric method is presented for the determination of tiapride in its pharmaceutical formulations. The method is based on the reaction of the aliphatic amino group on tiapride as n-electron donor with $p$-chloranilic acid as a $\pi$-acceptor in acetone to yield a reddish coloured charge transfer complex product which absorbed at $520 \mathrm{~nm}$. Beer's law is obeyed in the concentration range $10-100 \mu \mathrm{g} / \mathrm{mL}$ of tiapride with a correlation coefficient of 0.9999 . The optimum experimental parameters for the reaction have been studied. Statistical analysis of the results has been carried out revealing high accuracy and good precision. The suggested procedure could be used for the determination of tiapride in its pharmaceutical tablets.

Key Words: Tiapride, $p$-Chloranilic acid, Charge transfer complex, Pharmaceutical formulations, Spectrophotometry.

ᄂ - - - - - - - - - - - - - - - - - - - - - - - - -

\section{INTRODUCTION}

Tiapride (Fig. 1) is a substituted benzamide which exhibits antipsychotic properties ${ }^{1}$. It is an antagonist of the dopamine $\mathrm{D}_{2}$-receptors. Tiapride is a drug that selectively blocks $\mathrm{D}_{2}$ and $\mathrm{D}_{3}$-dopamine receptors in the brain. It is used to treat a variety of neurological and psychiatric disorders including dyskinesia, alcohol withdrawal syndrome, negative symptoms of psychosis and agitation and aggression in the elderly. In addition to its antipsychotic action, substituted benzamides present antiemetic, antidyskinetic and antihypertensive action ${ }^{1}$.

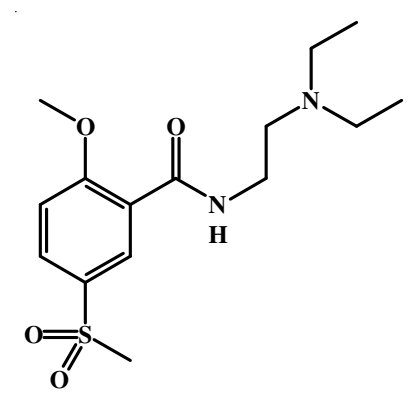

Fig. 1. Chemical structure of tiapride

The therapeutic importance of tiapride required the development of simple, sensitive, accurate and industrial quality control and clinical monitoring.

A review of the literature revealed that few methods have been described for its determination. Tiapride and its formu- lations are officially determined in the British Pharmacopoeia ${ }^{2}$ by nonaqueous titration with $\mathrm{HClO}_{4}$. The reported methods for determination of tiapride either in pharmaceuticals or in biological fluids include: titrimetry in nonaqueous medium with $\mathrm{HClO}_{4}{ }^{3}$, $\mathrm{HPLC}^{4-6}$, hydrophilic interaction liquid chromatography-tandem mass spectroscopy ${ }^{7}, \mathrm{TLC}^{8}, \mathrm{GC}^{9}$, capillary electrophoresis ${ }^{10}$, IR-spectroscopy ${ }^{11}$, differential pulse anodic voltammetry $^{12}$, selective membrane sensors ${ }^{13}$, flow-injection chemiluminescence $^{14}$ and spectrofluorimetry ${ }^{6}$. Derivative spectrophotometric methods ${ }^{6}$ were used for the determination of tiapride in pharmaceutical preparations and human plasma, but only one visible spectrophotometric method was found in the literature for its determination by its reaction with tropaeolin $\mathrm{OO}$ (TOO) at pH 5 to yield a yellowish ion-pair complex ${ }^{15}$.

However, the reported methods of the studied drug suffered from one or more disadvantage such as poor sensitivity, rigid $\mathrm{pH}$ control, heating, complicated experimental setup and meticulous control of experimental variables.

The aim of the present study was to develop a new, simple, sensitive and reliable visible spectrophotometric method for the fast control analysis of tiapride in pure form and in its dosage forms based on the formation of charge transfer complex. The results obtained were satisfactorily accurate and precise.

\section{EXPERIMENTAL}

A Unicam UV-visible spectrometer, Helios Alpha: Helios Beta model with $1 \mathrm{~cm}$ cuvette (Biochrom, England) was used 
equipped with $1 \mathrm{~cm}$ quartz cuvettes for the $\lambda_{\max }$ determination and all absorbance measurements.

Pure tiapride was obtained from Janssen Pharmaceutica Co./Belgica. Pharmaceutical formulations were obtained from local markets, as Tiapridal tablets (100 mg tiapride/tablet) B.N. 20024, produced by Synthelabo Laboratories. All chemicals used were of analytical reagent-grade quality and solvents were of spectroscopic grade. Distilled water was used throughout this work. $0.014 \mathrm{~mol} / \mathrm{L} p$-chloranilic acid (MERCK)was prepared in acetone (BDH AnalaR), aqueous solution of 0.1 $\mathrm{mol} / \mathrm{L} \mathrm{NaOH}$ was also prepared and dimethyl formamide(BDH Analar) was used.

Standard solution: Standard stock solution of pure tiapride $(1 \mathrm{mg} / \mathrm{mL})$ was prepared by dissolving $10 \mathrm{mg}$ of pure tiapride in $2 \mathrm{~mL}$ dimethyl formamide in a $10 \mathrm{~mL}$ volumetric flask, a drop of phenolphthalein indicator was added followed by the addition of $0.1 \mathrm{~mol} / \mathrm{L} \mathrm{NaOH}$ until the appearance of a pink colour and then diluted with acetone to the mark.

Construction of calibration curve: Calibration curve was constructed according to the optimum conditions in Table- 1 . Accurately measured aliquots from stock solution of tiapride equivalent to $10-100 \mu \mathrm{g} / \mathrm{mL}$ were transferred into a series of $10 \mathrm{~mL}$ volumetric flasks. $2 \mathrm{~mL}$ of $p$-chloranilic acid were added to each flask and left aside for $20 \mathrm{~min}$. Then the volumes were completed to the mark with acetone. The absorbances were measured at $520 \mathrm{~nm}$ against a reagent blank. The calibration curve was obtained by plotting the absorbances $v s$. final concentrations. Alternatively, the corresponding regression equation was derived.

TABLE- 1

CHARACTERISTIC PARAMETERS OF THE REGRESSION

EQUATION AND ASSAY VALIDATION RESULTS OF THE PROPOSED SPECTROPHOTOMETRIC METHOD FOR TIAPRIDE DETERMINATION

\begin{tabular}{lc}
\hline \multicolumn{1}{c}{ Parameter } & Value \\
\hline$\lambda_{\max }(\mathrm{nm})$ & 520 \\
Linearity $(\mu \mathrm{g} / \mathrm{mL})$ & $10-100$ \\
Regression: & \\
$\quad$ Slope & 0.008 \\
$\quad$ Intercept & 0.0094 \\
Correlation coefficient $(\mathrm{r})$ & 0.9999 \\
LOD $(\mu \mathrm{g} / \mathrm{mL})$ & 1.89 \\
LOQ $(\mu \mathrm{g} / \mathrm{mL})$ & 6.3 \\
Accuracy $($ Mean $\pm \mathrm{SD} \%)$ & $99.898 \pm 0.445$ \\
\hline
\end{tabular}

Procedure for dosage forms: Weighed accurately a quantity of the mixed contents of 10 pulverized tablets equivalent to $10 \mathrm{mg}$ of the drug. Transferred into a small conical flask and dissolved in $2 \mathrm{~mL}$ of dimethyl formamide. Shake and added one drop of phenolphthalein indicator. Add $0.1 \mathrm{~mol} / \mathrm{L}$ $\mathrm{NaOH}$ until appearance of a pink colour. Filtered in a $10 \mathrm{~mL}$ volumetric flask and complete to volume with acetone. The obtained solution labeled to contain $1.0 \mathrm{mg} / \mathrm{mL}$ tiapride was analyzed by the proposed method as described above using the standard addition method.

\section{RESULTS AND DISCUSSION}

$\pi$-Acceptors like $p$-chloranilic acid reacts with basic nitrogenous compounds as n-donors to form charge transfer complexes or radical anions according to the polarity of the solvent used. Tiapride has nitrogen centers which can act as n-electron donors (the amino groups) and are responsible for the formation of charge transfer complexes with $p$-chloranilic acid as a $\pi$-electron acceptor.

Tiapridere reacts with $p$-chloranilic acid in acetone forming a reddish coloured product which exhibits absorption maxima at $520 \mathrm{~nm}$ (Fig. 2).

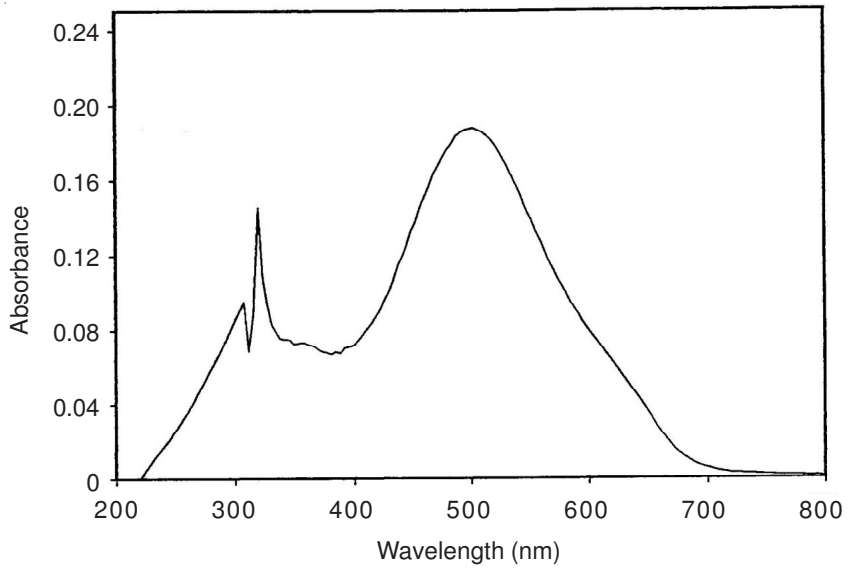

Fig. 2. Absorbance spectrum of $20 \mu \mathrm{g} / \mathrm{mL}$ tiapride/ $p$-chloranilic acid charge-transfer complex in acetone

Since a polar solvent is used (acetone), this band may be attributed to the formation of $p$-chloranilic acid radical anions. The reaction may be represented by the following equation:

$$
\begin{aligned}
& \text { Polar solvent } \\
& \mathrm{D}^{\bullet \bullet}+\mathrm{A} \longrightarrow[\mathrm{D}: \mathrm{A}] \longrightarrow \mathrm{D}^{+}+\mathrm{A}^{\bullet-} \\
& \text { n-donor } \pi \text {-acceptor complex radical anions }
\end{aligned}
$$

Optimization of reaction variables: Optimum reaction variables for quantitative determination of the formed chargetransfer complex was established via various preliminary experiments such as choice of organic solvent, the concentration and volume of the reagent and the effect of time.

Acetone was found to be the solvent of choice for tiapride to affect its dissolution.

The effect of reagent concentration was studied by using different concentrations of $p$-chloranilic acid in the range of $0.02-0.05 \mathrm{~mol} / \mathrm{L}$ to react with $20 \mu \mathrm{g} / \mathrm{mL}$ tiapride. It was found that $0.014 \mathrm{~mol} / \mathrm{L}$ was the suitable concentration of $p$-chloranilic acid which gave the highest absorbance of the complex formed (Fig. 3).

In order to establish the optimum volume of $0.014 \mathrm{~mol} / \mathrm{L}$ $p$-chloranilic acid, tiapride was allowed to react with different volumes of $p$-chloranilic acid in range of volumes between 1.0-6.0 mL. A volume of $2.0 \mathrm{~mL}$ of $0.014 \mathrm{~mol} / \mathrm{L} p$-chloranilic acid was required for higher absorbance value of the complex in acetone at the wavelength of maximum absorbance (Fig. 4).

Maximum colour intensity at ambient temperature was obtained with $p$-chloranilic acid after $20 \mathrm{~min}$ and remained stable for more than $1 \mathrm{~h}$ as shown in Fig. 5.

Composition of the charge-transfer complex: Job's method ${ }^{16}$ of continuous variations of equimolar solutions was employed to establish the composition of the charge transfer complex formed between tiapride and $p$-chloranilic acid. 


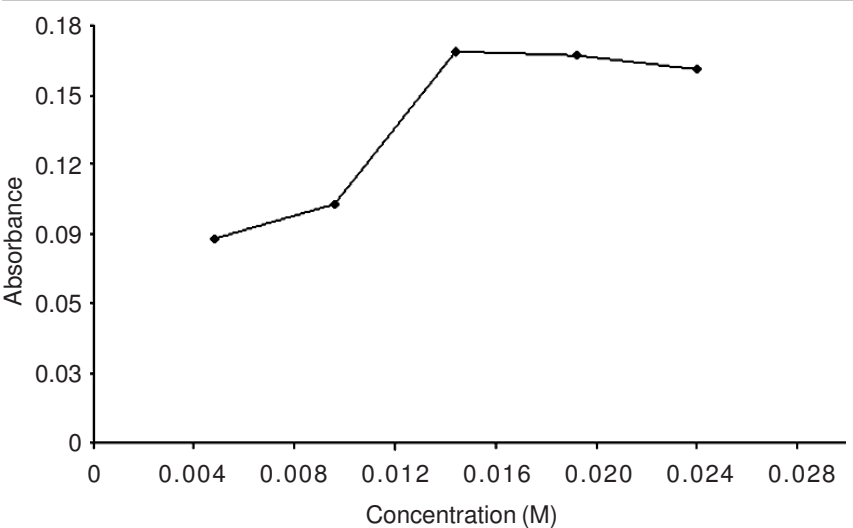

Fig. 3. Effect of $p$-chloranilic acid concentration on the absorbance of 20 $\mu \mathrm{g} / \mathrm{mL}$ tiapride/ $p$-chloranilic acid charge-transfer complex at 520 $\mathrm{nm}$

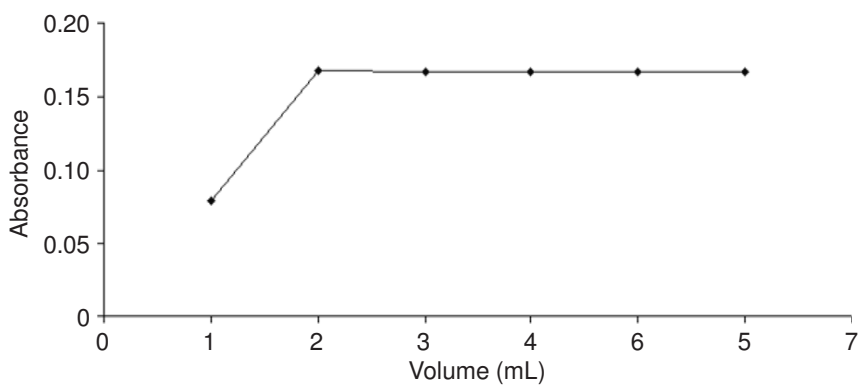

Fig. 4. Effect of volume of $0.014 \mathrm{~mol} / \mathrm{L} p$-chloranilic acid on the absorbance of $20 \mu \mathrm{g} / \mathrm{mL}$ tiapride $/ p$-chloranilic acid charge-transfer complex at $520 \mathrm{~nm}$

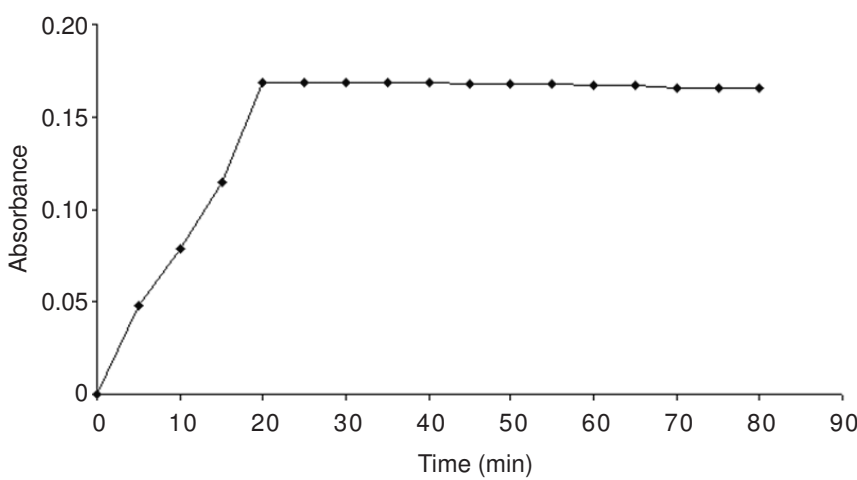

Fig. 5. Effect of time on the stability of $20 \mu \mathrm{g} / \mathrm{mL}$ tiapride $/ p$-chloranilic acid charge-transfer complex at $520 \mathrm{~nm}$

In this method, solutions of $3.04 \times 10^{-4} \mathrm{~mol} / \mathrm{L}$ standard tiapride solution and $3.04 \times 10^{-4} \mathrm{~mol} / \mathrm{L} p$-chloranilic acid were mixed in varying volume ratios in such a way that the total volume of each mixture was kept the same at $10 \mathrm{~mL}$. The absorbance of each solution was plotted after 20 min against the mole fraction of tiapride.

The plot reached a maximum value at a mole fraction of 0.5 (Fig. 6) which indicated the formation of 1:1 (tiapride: $p$-chloranilic acid) charge transfer complex and confirm the presence of one basic nitrogen containing group.

Method validation: Under optimum experimental conditions, the method was tested for linearity, specificity, precision and reproducibility. With the above spectrophotometric method, linear regression equation was obtained. The regression plot showed that linear dependence of the relative absorbance intensities on the concentrations of the studied drug

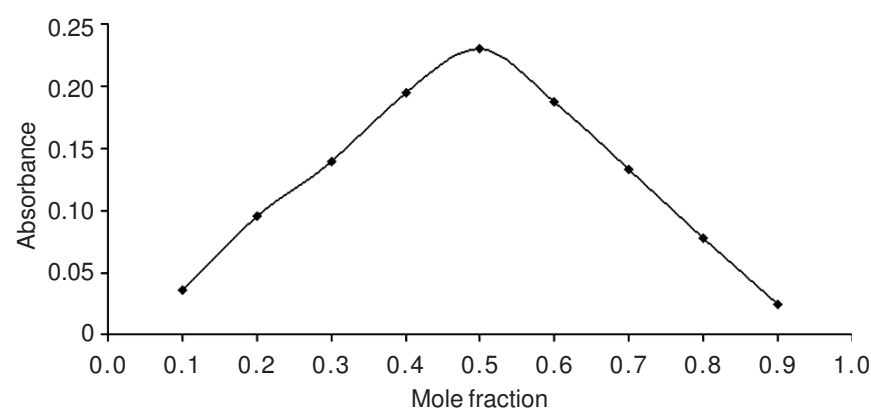

Fig. 6. Determination of the stoichiometry of the reaction of $3.04 \times 10^{-4}$ mol/L tiapride with $3.04 \times 10^{-4} \mathrm{~mol} / \mathrm{L} p$-chloranilic acid by continuous variations method at $520 \mathrm{~nm}$

was in the range of $10-100 \mu \mathrm{g} / \mathrm{mL}$ for tiapride with $p$ chloranilic acid (Table-1).

Statistical evaluation of the experimental data was adopted (Table-1). The good linearity of the calibration graph and the negligible scatter of the experimental points are clearly evident by the correlation coefficient (close to 1 ).

The validity of the method could be proved by analyzing authentic samples of the drug. The results obtained in Table- 2 are in good agreement with those given by the comparison $\operatorname{mathod}^{14}$.

TABLE- 2

STATISTICAL COMPARISON BETWEEN THE RESULTS

OF THE PROPOSED METHOD FOR DETERMINATION OF TIAPRIDE AND A PUBLISHED METHOD

\begin{tabular}{lcc}
\hline \multicolumn{1}{c}{ Value } & Proposed method & Published method $^{14}$ \\
\hline Mean & 99.898 & 99.30 \\
S.D. & 0.445 & 0.700 \\
$\mathrm{n}$ & 10 & 5 \\
Variance (S.D. $)^{2}$ & 0.198 & 0.49 \\
$\mathrm{t}$ & $(2.160)^{*}$ & 2.032 \\
$\mathrm{~F}$ & $(3.63)^{*}$ & 2.475 \\
\hline *Figures in parentheses are the theoretical $\mathrm{t}-$ and $\mathrm{F}-$ values at $\mathrm{P}=$ \\
\multicolumn{2}{l}{0.05 confidence limit. }
\end{tabular}

The specificity of the method was investigated by observing that no interferences were encountered from common tablet excipients. The simplicity of the method and the stability of the reaction product permitted the determination of tiapride in commercial tablets.

The accuracy and validity of the proposed method was ascertained by performing the recovery experimental via the standard addition procedure. Pre-analyzed tablet powder was spiked with pure drug at eight different concentration levels and the total was measured using the proposed method. The determination with each level was repeated three times and the results of this study presented in Table- 3 indicated that the commonly excipients present in the formulations did not interfere in the assay.

\section{Conclusion}

The proposed method is simple, accurate, inexpensive, sensitive and require minimum equipments and chemicals. The results are reproducible. This method can be used as general method for spectrophotometric determination of tiapride in bulk powder and in dosage forms, have many advantages over separation techniques such as HPLC, are reduced cost and 


\begin{tabular}{ccccc}
\hline \multicolumn{5}{c}{ TABLE-3 } \\
RESULTS OF RECOVERY STUDY BY STANDARD-ADDITION \\
METHOD FOR DETERMINATION OF TIAPRIDE IN \\
PHARMACEUTICAL FORMULATIONS \\
\hline \multirow{3}{*}{ Formulation } & $\begin{array}{c}\text { Found } \\
(\mathrm{mg})\end{array}$ & $\begin{array}{c}\text { Pure added } \\
(\mu \mathrm{g} / \mathrm{mL})\end{array}$ & $\begin{array}{c}\text { Pure found } \\
(\mu \mathrm{g} / \mathrm{mL})\end{array}$ & $\begin{array}{c}\text { Pure } \\
\text { recovered } \\
(\%)^{*}\end{array}$ \\
\hline & & 10 & 10 & 100.00 \\
Tiapridal & & 20 & 20 & 100.00 \\
tablets & 99.15 & 30 & 29.75 & 99.17 \\
$(100$ & & 40 & 40.25 & 100.63 \\
mg/tablet) & 50 & 50.13 & 100.26 \\
B.N. 20024 & 60 & 59.88 & 99.80 \\
& 70 & 69.63 & 99.47 \\
& & 80 & 79.88 & 99.85 \\
Mean \pm S.D. & & & $99.88 \pm 1.008$ \\
\hline *Mean value of three determinations.
\end{tabular}

speed with high accuracy. The proposed method is suitable for routine quality control.

\section{ACKNOWLEDGEMENTS}

This project was supported by King Saud University, Deanship of Scientific Research, College of Science Research Center.

\section{REFERENCES}

1. R.F. Spano, M. Trabucchi, G.U. Corsini and G.L. Gessa, Sulpiride and Other Benzamides, Experimental and Clinical Pharmacology, Raven Press, New York (1979).

2. The British Pharmacopoeia, Her Msjesty's Stationary Office, London Vol. 1, p. 488 (2005).

3. B. Wu, M. Lu, Y. Wang and X. Fang, Yaowu-Fenxi-Zazhi, 5, 20 (1985).

4. M. Nobilis, Z. Vybiralova, B. Szotakova, K. Sladkova, M. Kunes and Z. Svoboda, J. Chromatogr. B: Anal. Technol. Biomed. Life Sci., 879, 3845 (2011).

5. R. Chiba, A. Ogasawara, T. Kubo, H. Yamazaki, M. Umino and Y. Ishizuka, Anal. Sci., 19, 785 (2003).

6. F.H. Metwally, M. Abdelkawy and N.S. Abdelwahab, J. AOAC Int., 90, 1554 (2007).

7. Y. Moon, I.B. Paek, H.H. Kim, H.Y. Ji, H.W. Lee, H.G. Park and H.S. Lee, Arch. Pharm. Res., 27, 901 (2004).

8. A.B. Skorniakov, R.A. Kalekin and D.S. Lazarian, Sud. Med. Ekspert., 49, 37 (2006).

9. A. Valli, A. Polettini, P. Papa and M. Montagna, Ther. Drug Monit., 23, 287 (2001).

10. J. Li, F. Zhao and H. Ju, J. Chromatogr. B: Anal. Technol. Biomed. Life Sci., 835, 84 (2006).

11. R.A. Kalekina, E.M. Salomatin, V.A. Kalekina, A.A. Volkova and V.K. Dadabaev, Sud. Med. Ekspert., 53, 33 (2010).

12. S.I. Zayed, Anal. Sci., 27, 535 (2011).

13. F.H. Metwally, Yakugaku Zasshi, 127, 1267 (2007).

14. F.A. Aly, N.A. Alarfaj and A.A. Alwarthan, Talanta, 54, 715 (2001).

15. N.A. Alarfaj, A.A. Mostafa and Z.A. Alghamdi, Asian J. Chem., 24, 5507 (2012).

16. J. Inczedy, Analytical Applications of Complex Equilibria, College House, Westergate, UK (1976). 